\title{
Results of Geophysical Trials to profile the Kimberlite/Host Rock Contacts at Venetia Mine and the BK-9 Pipe
}

\author{
C.C. Pretorius ${ }^{1}$, J. Blume ${ }^{2}$, H. Lütjen ${ }^{1}$, and K. Trofimczyk ${ }^{1}$ \\ 1. Geophysical Services Department, Anglo American Corporation of South Africa Ltd, PO Box 61587, Marshalltown \\ 2107, South Africa \\ 2. J. Blume, Geoelectrical Consultant, 110 Seventh Road, Kew, 2090, Johannesburg, South Africa
}

\begin{abstract}
In order to make a decision on the optimum depth to which an open pit kimberlite diamond mine should be planned it is necessary to have good information on the shape and grade of the kimberlite pipe, as well as any structures in the host rock. Any geophysical technique which can rapidly and costeffectively outline pipes in three-dimensions at depth would be of great assistance in evaluating kimberlites, especially where decisions have to be made quickly and on limited drilling information.

A number of surface and borehole geophysical techniques for pipe delineation were tested at Venetia Mine and BK-9 kimberlite pipe in Botswana during 1996 and 1997. These techniques included 3D DC-Resistivity Imaging, Surface Seismic Reflection, Seismic Tomography and Radio-Wave Tomography.
\end{abstract}

\section{D DC-Resistivity Imaging}

Surface and down-hole resistivity imaging techniques are increasing in popularity and show great promise in mapping and outlining geological targets and structures. However, a great deal of work is needed to reach a better understanding of "electrical resistivity tomography". Commercial instrumentation has improved during the last three years, but unfortunately software development has not kept pace.

In order to test and develop a such system embarked upon with three main phases:

- Data acquisition and preparation

- Equipment and software development

- Development of the technique for specific prospecting and mining applications.

Promising results have emerged from the first test measurements carried out at BK9 in 16 combined borehole and surface profiles with a 6-channel multi-electrode DC resistivity system.

The kimberlite/country rock contact has been profiled up to depths of $200 \mathrm{~m}$ on the north-eastern edge of the pipe. Generally the first results show a distinct low/high resistivity contrast between pipe and 
country rock (basalt) up to a depth of $100 \mathrm{~m}-120 \mathrm{~m}$. Below this depth a high/low contrast due to high resistive structures inside the pipe and the low resistive surrounding sandstone is mapped.

Experiments are currently underway to increase the depth of investigation and improve the resolution of the technique.

\section{Radio-Wave and Seismic Tomography}

Comments on the performance of these techniques will also be discussed.

To the best of our knowledge, this is the first time that geophysical techniques are being applied to map the shape of a kimberlite at depth and, if successful, the project would ensure significantly assist in future mine planning and development. 